\title{
Synapsin Polymorphisms Could Be Correlated with Stroop Simple Reaction Time Scores
}

\author{
Ahmet Buber1, Burge Kabukcu Basay¹, Omer Basay', Onder Ozturk1, Huseyin Alacam², \\ Kemal Utku Yazici ${ }^{3}$, Ali Bacanli4, Mustafa Ertan Ay5, Mehmet Emin Erdal'5, Hasan Herken²*, \\ Eyup Sabri Ercan 6 \\ ${ }^{1}$ Child and Adolescent Psychiatry Department, Pamukkale University Medical Faculty, Denizli, Turkey \\ ${ }^{2}$ Psychiatry Department, Pamukkale University Medical Faculty, Denizli, Turkey \\ ${ }^{3}$ Child and Adolescent Psychiatry Department, Firat University Medical Faculty, Elazıg, Turkey \\ ${ }^{4}$ Child and Adolescent Psychiatry Department, Gaziantep Children Hospital, Gaziantep, Turkey \\ ${ }^{5}$ Medical Biology and Genetics Department, Mersin University Medical Faculty, Mersin, Turkey \\ ${ }^{6}$ Child and Adolescent Psychiatry Department, Ege University Medical Faculty, Izmir, Turkey \\ Email: ahmetbuber@gmail.com, burgekabukcu@yahoo.com,omer_basay@yahoo.com, \\ dr.onder81@yahoo.com.tr, dr.huseyinalacam@hotmail.com, uyazici@firat.edu.tr, ali_bacanli@yahoo.com, \\ ertanay35@yahoo.com, mehmeteminerdal@gmail.com, "hherken@pau.edu.tr, eyercan@hotmail.com
}

Received 12 October 2015; accepted 3 January 2016; published 6 January 2016

Copyright (C) 2016 by authors and Scientific Research Publishing Inc.

This work is licensed under the Creative Commons Attribution International License (CC BY).

http://creativecommons.org/licenses/by/4.0/

c) (i) Open Access

\section{Abstract}

Objective: The aim of this study was to research the relationship between Attention Deficit Hyperactivity Disorder (ADHD) and the synapsin III $-196 \mathrm{G}>\mathrm{A}$ and $-631 \mathrm{C}>\mathrm{G}$ polymorphisms and study their impact on neurocognition and behavior in Turkish children and adolescents. Methods: A total of 201 ADHD-diagnosed children and 100 control subjects aged between 8 and 15 years were recruited, and genetic material was obtained from saliva. In the diagnostic assessments, the $\mathrm{K}$ SADS-PL semi-structured interview was applied. Children with any comorbid psychiatric diagnosis (with the exclusion of oppositional defiant disorder (ODD)), medical conditions, prior psychotropic drug use history or IQ score below 80 were excluded. For the behavioral and ADHD symptom assessments, the Turgay DSM-IV Disruptive Behaviors Rating Scale, Teacher Report Form (TRF) and Child Behavior Checklist (CBCL) were completed by the parents and teachers. Neurocognitive profiles were evaluated with the CNS-Vital Signs computerized neurocognitive test battery. Results: No significant difference in ADHD prevalence was observed between subjects with the synapsin III gene $-196 \mathrm{G}>\mathrm{A}$ polymorphism and $-631 \mathrm{C}>\mathrm{G}$ polymorphisms. These polymorphisms were also not associated with subtypes of ADHD. We found a relationship between both polymorphisms and

\footnotetext{
*Corresponding author.
}

How to cite this paper: Buber, A., Basay, B.K., Basay, O., Ozturk, O., Alacam, H., Yazici, K.U., Bacanli, A., Ay, M.E., Erdal, M.E., Herken, H. and Ercan, E.S. (2016) Synapsin Polymorphisms Could Be Correlated with Stroop Simple Reaction Time Scores. American Journal of Molecular Biology, 6, 25-32. http://dx.doi.org/10.4236/ajmb.2016.61003 
Stroop simple reaction time. Conclusion: Synapsin's effect could be limited during childhood, but synapsin polymorphisms could be associated with Stroop simple reaction time.

Keywords

Attention Deficit Hyperactivity Disorder, Synapsin III, Association, Cognitive Function

\section{Introduction}

Attention-Deficit/Hyperactivity Disorder (ADHD) is a prevalent childhood neuropsychiatric condition, with an approximate worldwide prevalence of $5 \%$ in school-age children [1]. According to the current criteria of the Diagnostic and Statistical Manual of Mental Disorders, $5^{\text {th }}$ edition (DSM-V), ADHD is defined as a persistent pattern of inattention and/or hyperactivity-impulsivity that interferes with development [2]. Although ADHD maybe the most studied condition in child psychiatry worldwide [3], the precise causes and mechanisms are not yet completely understood. Genetics studies support a strong genetic contribution for ADHD development. The first genetic studies targeted dopaminergic genes, but they only explained a small part of ADHD heritability [4]. It is suggested that the modulation of neurotransmitter release and synaptogenesis might be involved in the pathophysiology of ADHD, as well [5].

Synapsins are a family of neuron-specific phosphoproteins [6] and synaptic vesicle proteins that play a very important role in the regulation of neurotransmission and synaptogenesis [7]. In mammals, three synapsin genes (I, II, and III) have been described [7]. Kao et al. cloned and characterized synapsin III from human DNA; it is located on chromosome 22 [8]. Synapsin III appears to play a significant role in early neurodevelopmental processes and also neurogenesis and axonogenesis [9]. Another important role of synapsin III is involved in synaptic transmission, especially dopamine release [10]. Studies have investigated genes encoding the proteins that have roles in the modulation of neurotransmitter release and ADHD, such as SNAP-25 gene (the synaptosomal-associated protein) [11], synaptobrevin-2 (VAMP2) and syntaxin 1A genes [12]. This inquiry about synapsin III in ADHD is commendable as ADHD is related to the release of neurotransmitters, especially dopamine.

The Synapsin III gene has been studied in schizophrenia and was mapped to chromosome 22 at 22q12-q13 [13]. This region is theorized to be involved in schizophrenia, but no relationship between synapsin III gene polymorphisms and schizophrenia [14] has been noted. Currently, there are two studies that have evaluated the relationship between Synapsin III and ADHD. One of the studies found no relationship between synapsin III gene polymorphisms and ADHD [15]. In the other study, Kenar et al. found a relationship between the $-631 \mathrm{C}>\mathrm{G}$ polymorphism and ADHD; however, they found no relationship between the -196G>A polymorphism and ADHD in adult Turkish patients [16].

The purpose of this study was to research the relationship between ADHD and the synapsin III gene and to investigate the neuropsychological tests in $-196 \mathrm{G}>\mathrm{A}$ and $-631 \mathrm{C}>\mathrm{G}$ polymorphisms in a clinical sample of children and adolescents diagnosed with ADHD, as well as in typically developing Turkish children and adolescents.

\section{Methods}

\subsection{Study Design and Participants}

In the present study, 201 ADHD-diagnosed children and 100 control subjects were evaluated, and the genetic material was assessed for the determination of synapsin III genotypes. The study participants were assessed in the child and adolescent psychiatry clinic of Ege University from December 2011 to March 2013.

The ADHD and control group subjects were recruited among children satisfying the following criteria: aged between 8 and 15 years, an IQ score above 80, living with his/her own family, attending a normal school, no history of head injury with unconsciousness, no history of neurological or other serious medical diseases or the constant use of prescribed medications for medical conditions, and no history of prior use of stimulants or use of psychotropic medication within the last six months. For the ADHD subjects, any psychiatric disorder other than 
oppositional defiant disorder (ODD) was an exclusion criterion; for the control subjects, any psychiatric disorder was not allowed.

Ethical approval was granted and approved by the Pamukkale University Research Ethics Committee in accordance with the Helsinki Declaration. Written consent was taken from parents of the children both for the ADHD group and typical development (TD) group.

\subsection{Diagnostic Procedures}

The Child Behavior Checklist (CBCL) [17], the Teacher's Report Form (TRF) [18] and the DSM-IV Disruptive Behavior Disorders Rating Scale- teacher and parent forms [19] were completed by parents and teachers. Subjects with an inattentive score more than one standard deviation greater than the age norms for these scales were invited to participate in the diagnostic part of the study. This procedure was performed to guarantee that inattentive symptoms were adequately represented in all ADHD types assessed. Initially, a semi-structured interview (Kiddie-Schedule for Affective Disorders and Schizophrenia, present and life time version-K-SADS-PL) was administered to parents by a senior child psychiatry resident [20]. The same psychiatrist also performed a mental status examination of each child. Then, an estimated IQ was obtained by using vocabulary and block design subtests of WISC-R.

Two experienced child psychiatrists who were blind to the first diagnostic assessment conducted a confirmatory second diagnostic interview for those with a positive ADHD diagnosis in the first KSDAS-PL interview. The parents (mostly mothers-93\%) and subjects were also interviewed according to the K-SADS-PL. "A best estimate procedure" was used to determine the final diagnoses [21]. Thirteen subjects were excluded from the second diagnostic part of the study. Three subjects refused to attend the second diagnostic interview, and a disagreement between interviewers on ADHD types/comorbid diagnoses occurred for 10 cases. Unrelated healthy controls were recruited from the same community. The same diagnostic procedure was applied for the assessment of controls. However, we required that TD subjects had inattentive scores one standard deviation below the mean for the child's age on the CBCL, TRF, ADHD-RS-IV scales. A sample of 201 children with ADHD and 100 control subjects were included in the study.

\subsection{Neurocognitive Assessments: CNS Vital Signs}

CNS Vital Signs is a computerized neurocognitive test battery that is composed of the following 7 tests: verbal and visual memory, finger tapping, symbol digit coding, the Stroop Test, a test of shifting attention, and the continuous performance test. The results are scored in the following 6 domains: neurocognitive index, memory, psychomotor speed, reaction time, comprehensive attention, and cognitive compliance. These scores are calculated according to the age group of the cases. This test is generally completed in 30 minutes. This battery is a sensitive tool for evaluating the performance of children and adolescents with ADHD [22].

\subsection{Genotyping: DNA Isolation and Molecular Analysis}

For the amplification of the synapsin III gene -196G>A (rs133945) polymorphism, DNA was isolated from peripheral blood leukocytes by the standard phenol/chloroform method and genotyped by the polymerase chain reaction-restriction fragment length polymorphism method. PCR was performed with a personal thermal cycler (Techgene), using SYN2 F-5'-T CCTTTCCAGAAGGATGTCC-3'/SYN2 R-5'AAGCCAACAAATACAT AAGTGGAGA-3'primers. For the amplification of the synapsin III gene -631C>G (rs133946) polymorphism, DNA was isolated from saliva. PCR was performed with a personal thermal cycler (Techgene), using SYN1 F-5'-AGGCATGTACTTGCGTTACC-3'/SYN1 R-5'-ACCAAATGACTACAAAGATGTACCA-3' primers.

\subsection{Data Analyses}

Group differences in the demographic variables were examined by the Kruskal-Wallis test for nonparametric data, and categorical comparisons were performed by Chi Square Test. Associations between the study groups and gene polymorphisms were examined using chi-squared analyses. Group comparisons in the scale and neurocognitive tests scores according to Synapsin III genotypes were performed with One-Way Analysis of Variance (One-Way ANOVA) for the parametric continuous data and with the Kruskal-Wallis Test for the nonparametric continuous data. Significant differences between pairs of groups were detected using Tukey's posthoc test for the parametric data and the Mann-Whitney U Test for the nonparametric data. p-values $<0.05$ were con- 
sidered statistically significant. SPSS (Statistical Package for Social Sciences) version 17.0 for Windows was used for statistical analysis of the data.

\section{Results}

A total of 201 ADHD patients and 100 healthy controls were admitted to the study. The mean age of the study group was $10.78 \pm 2.01$, and the mean age of the control group was $10.73 \pm 1.92$. There was no significant difference between the study and control groups regarding age ( $\mathrm{p}>0.05$ ). The study group consisted of $78 \%$ boys and $22 \%$ girls. The control group consisted of $55 \%$ boys and $45 \%$ girls. The difference in sex composition between the groups was significant ( $p>0.001)$ (Table 1$)$.

\subsection{Synapsin III Gene-196G>A Polymorphism Results of the Groups}

Genomic DNAs for the synapsin III gene -196G>A polymorphism could not be obtained from 1 of the 201 patients and 1 of the 100 control subjects because of technical problems and they were not included into the results.

The frequency of the synapsin III gene -196G>A polymorphism was compared between groups. The G allele (patient: $51.3 \%$, control: $47.5 \%$ ) in the patient group, the A allele in the control group (patient: $48.7 \%$, control $52.5 \%)(p=0.472)$ : and the G/A genotype (patient: $52.5 \%$, control: $51.5 \%)(p=0.734)$ were observed most often among the groups, and no significant difference was found between the groups. No significant difference was found between the groups in terms of the presence of the $G(p=0.472)$ or A allele $(p=0.597)$ (Table 2).

In comparing the ADHD subtypes and genotypes with the control group, the G/A genotype was most prevalent in all the three ADHD subtypes, in the inattentive type (44\%), in the restrictive type (52\%), in the combined type (57\%) and also in the control group (51.5\%). The difference between the subtypes and the control group was not significant $(\mathrm{p}=0.812)$ (Table 3$)$.

\subsection{Neuropsychological Findings and Rating Scales of Synapsin III Gene -196G>A Polymorphism}

We compared the CNS-VS domain scores according to the polymorphism groups in the entire sample; we found

Table 1. Age and sex distribution of the subjects according to diagnosis.

\begin{tabular}{ccccccc}
\hline Group & Age (y) & p-value & Boysn (\%) & Girlsn (\%) & Totaln (\%) & p-value \\
\hline ADHD & $10.78 \pm 2.01$ & \multirow{2}{*}{$0.872^{*}$} & $157(78 \%)$ & $44(22 \%)$ & $201(100 \%)$ & $\mathbf{0 . 0 0 0}^{* *}$ \\
Controls & $10.73 \pm 1.92$ & & $55(55 \%)$ & $45(45 \%)$ & $100(100 \%)$ & \\
Total & $10.7 \pm 0.98$ & & $212(70.4 \%)$ & $89(29.6 \%)$ & $301(100 \%)$ & \\
\hline
\end{tabular}

*Mann Whitney U nonparametric test. ${ }^{* *}$ Chi Square Test.

Table 2. Allele and genotype frequencies of the Synapsin III gene -196G>A polymorphism.

\begin{tabular}{|c|c|c|c|}
\hline Allele frequencies & ADHDn (\%) & Controln (\%) & p-value \\
\hline $\mathrm{G}$ & 205 & 94 & \multirow{3}{*}{0.472} \\
\hline $\mathrm{A}$ & 195 & 104 & \\
\hline Total & 400 & 198 & \\
\hline Genotype frequencies & n (\%) & n (\%) & p-value \\
\hline $\mathrm{G} / \mathrm{G}$ & 50 & 22 & \multirow{4}{*}{0.734} \\
\hline $\mathrm{G} / \mathrm{A}$ & 105 & 51 & \\
\hline $\mathrm{A} / \mathrm{A}$ & 45 & 26 & \\
\hline Total & 200 & 99 & \\
\hline Presence or absence of $G$ and $A$ alleles & n (\%) & n (\%) & p-value \\
\hline $\mathrm{G} / \mathrm{G}+\mathrm{G} / \mathrm{A}$ & $155(77.5 \%)$ & $73(73.7 \%)$ & 0.472 \\
\hline $\mathrm{A} / \mathrm{A}+\mathrm{G} / \mathrm{A}$ & $150(75 \%)$ & $77(77.7 \%)$ & 0.597 \\
\hline
\end{tabular}

Chi-square test was performed. ADHD, attention deficit hyperactivity disorder. 
statistical significance only for the Stroop simple reaction time $(\mathrm{p}=0.008)(\mathrm{GG}: 584.6 \pm 373.1$, GA: $451.6 \pm$ 267.4, AA: $502.9 \pm 269.8$, respectively, post hoc analyses (Tukey); GG > GA; p = 0.005). The neuropsychological performance of the GG, GA and AA groups within the ADHD group did not differ significantly. We also could not find any difference between the GG + GA when compared to AA, or the GG when compared to GA + AA in the ADHD group.

DSM-IV Disruptive Behavior Disorders Rating Scale-teacher and parent forms and Child Behavior Checklist subgroups of the Synapsin III gene -196G>A polymorphism GG, GA and AA groups did not differ significantly. We did not find any difference in the DSM-IV Disruptive Behavior Disorders Rating Scale- teacher and parent forms or Child Behavior Checklist subgroups of the Synapsin III gene -196G>A polymorphism GG, GA and AA groups among the entire group. We also compared groups according to GG + GA and AA, as well as GG and GA + AA, but again did not find any significant difference.

\subsection{Synapsin III Gene -631C>G Polymorphism Results of the Groups}

Genomic DNAs for the synapsin III gene -631C>G polymorphism could not be obtained from 1 of the 201 patients and 1 of the 100 control subjects because of technical problems and they were not included into the results.

The groups were compared according to the Synapsin III gene -631C $>\mathrm{G}$ polymorphism. The $\mathrm{C}$ allele (patient: 50.5\%, control: $48 \%)$ : in the patient group, the G allele in the control group (patient: $49.5 \%$, control $52 \%)(\mathrm{p}=$ $0.562)$ and the $\mathrm{C} / \mathrm{G}$ genotype (patient: $53.2 \%$, control: $52.5 \%)(\mathrm{p}=0.886)$ were most prevalent among the groups, and no significant difference was found between the groups. No significant difference was found between the groups in terms of the presence of the $C(p=0.650)$ or $G$ allele $(p=0.749)$ (Table 4).

In comparing the ADHD subtypes and genotypes with the control group, the $\mathrm{C} / \mathrm{G}$ genotype was most prevalent in all the three ADHD subtypes, in the inattentive type (44\%), in the restrictive type (50\%), in the combined type (61\%) and also in the control group (52.5\%). The difference between the subtypes and the control group was not significant $(\mathrm{p}=0.520)$ (Table 5).

Table 3. Synapsin III gene -196G $>$ A polymorphism genotype distribution of the ADHD subtypes and the control groups.

\begin{tabular}{cccccc}
\hline Genotype & Inattentive type n (\%) & Restrictive type n (\%) & Combined type n (\%) & Control & p-value \\
\hline GG & $15(30 \%)$ & $12(24 \%)$ & $23(23 \%)$ & $22(22.2 \%)$ & \\
GA & $22(44 \%)$ & $26(52 \%)$ & $57(57 \%)$ & $51(51.5 \%)$ & \\
AA & $13(26 \%)$ & $12(24 \%)$ & $20(20 \%)$ & $26(26.3 \%)$ & 0.812 \\
Total & 50 & 50 & 100 & 99 \\
\hline
\end{tabular}

Chi-square test was performed.

Table 4. Allele and genotype frequencies of the Synapsin III gene -631C $>\mathrm{G}$ polymorphism.

\begin{tabular}{|c|c|c|c|}
\hline Allele frequencies & ADHD n (\%) & Control n (\%) & p-value \\
\hline G & 203 & 95 & \multirow{3}{*}{0.562} \\
\hline A & 199 & 103 & \\
\hline Total & 402 & 198 & \\
\hline Genotype frequencies & n (\%) & n (\%) & p-value \\
\hline $\mathrm{C} / \mathrm{C}$ & 48 & 22 & \multirow{4}{*}{0.886} \\
\hline $\mathrm{C} / \mathrm{G}$ & 107 (53.2\%) & 52 (52.5\%) & \\
\hline $\mathrm{G} / \mathrm{G}$ & 46 & 25 & \\
\hline Total & 201 & 99 & \\
\hline Presence or absence of $C$ and $G$ alleles & n (\%) & n (\%) & p-value \\
\hline $\mathrm{C} / \mathrm{C}+\mathrm{C} / \mathrm{G}$ & $155(77.1 \%)$ & $74(74.7 \%)$ & 0.650 \\
\hline $\mathrm{G} / \mathrm{G}+\mathrm{C} / \mathrm{G}$ & $153(76.1 \%)$ & 77 (77.7\%) & 0.749 \\
\hline
\end{tabular}

Chi-square test was performed. ADHD, attention deficit hyperactivity disorder. 
Table 5. Synapsin III gene $-631 \mathrm{C}>\mathrm{G}$ polymorphism genotype distribution of the ADHD subtypes and the control groups.

\begin{tabular}{cccccc}
\hline Genotype & Inattentive type n (\%) & Restrictive type n (\%) & Combined type n (\%) & Control & p-value \\
\hline CC & $15(30 \%)$ & $12(24 \%)$ & $21(21 \%)$ & $22(22.2 \%)$ & \\
CG & $21(44 \%)$ & $25(50 \%)$ & $61(61 \%)$ & $52(52.5 \%)$ & 0.520 \\
GG & $14(26 \%)$ & $13(26 \%)$ & $19(19 \%)$ & $25(25.3 \%)$ & \\
Total & 50 & 50 & 100 & 99 & \\
\hline
\end{tabular}

Chi-square test was performed.

\subsection{Neuropsychological Findings and Rating Scales of Synapsin III Gene -631C>G Polymorphism}

We compared the CNS-VS domain scores of the CC, CG and GG groups in the entire sample, and we found a significant difference in the Stroop simple reaction time $(\mathrm{p}=0.002)$ (CC: $598.4 \pm 374.6$, CG: $448.2 \pm 259.1$, GG: $499.9 \pm 300.3$, respectively, post hoc analyses (Tukey); CC > CG; p $=0.001$ ). In comparing the CC, CG and GG groups, the only significant difference was in the Stroop simple reaction time $(\mathrm{p}=0.022)$ (CC: $598.0 \pm 373.2$, CG: $458.8 \pm 248.1$, GG: $536.7 \pm 310.3$, respectively) in the ADHD group. We did not find any difference between the CC + CG and GG groups in neuropsychological performance. We again found a difference in Stroop simple reaction time in comparing the Synapsin III gene -631C > G polymorphism CC and CG + GG groups (p $=0.020$ ) (CC: $598.0 \pm 373.2$, CG + GG: $48227 \pm 269.6$, respectively).

DSM-IV Disruptive Behavior Disorders Rating Scale - teacher and parent forms and Child Behavior Checklist subgroups of the Synapsin III gene -631C>G polymorphism CC, CG and GG groups did not differ significantly. We did not find any difference in the DSM-IV Disruptive Behavior Disorders Rating Scale-teacher and parent forms and Child Behavior Checklist subgroups of the Synapsin III gene -631C>G polymorphism CC, CG and GG groups in the entire group. We also compared the CC+CG and GG groups and the CC and CG + GG groups, but again, we did not find any significant difference.

\section{Discussion}

In the present study, we did not observe a relationship between ADHD and the -196G>A polymorphism of the synapsin III gene. These findings are compatible with the literature. Makkar et al. investigated the relationships of five polymorphisms of the synapsin III gene; rs133946 (exon 5), rs133945 (exon 5), rs242089 (intron 5), rs3788459 (intron 6) and rs1056484 (3'UTR) with ADHD in 177 families with 220 affected children. They found no relationship between the -196G>A polymorphism and ADHD [15]. In the study with a total of 139 patients with adult ADHD and 106 healthy controls, no significant difference was observed between the groups in the prevalence of the synapsin III gene -196G>A polymorphism [16]. This polymorphism may not have an effect on ADHD symptoms.

We did not find a relationship between ADHD and the $-631 \mathrm{C}>\mathrm{G}$ polymorphism of the synapsin III gene. The literature on ADHD and the $-631 \mathrm{C}>\mathrm{G}$ polymorphism is controversial. Makkar et al. found no relationship in children [15]. However, Kenar et al. found a significant relationship between ADHD and the -631C>G polymorphism of the synapsin III gene in adult patients [16]. The difference between the aforementioned adult study and ours may be because their patient and control groups consisted of adults and our groups consisted of children and adolescents. Additionally, this polymorphism may not have a major effect on ADHD symptoms during childhood but may present at adulthood. It is indicated that synapsin III plays a much earlier role in neurodevelopment [9], but interestingly, we did not find a relationship with ADHD in childhood.

There have been no data on neuropsychological performance and the -196G>A polymorphism and $-631 \mathrm{C}>\mathrm{G}$ polymorphism until now. In the entire group, for the -196G>A polymorphism, the GG group had higher Stroop test scores than the other two groups and significantly higher scores than the GA group. Also in the entire group, for the $-631 \mathrm{C}>\mathrm{G}$ polymorphism, the CC group's Stroop test scores were higher than the other groups'. There are several versions of the Stroop test, and the modification adopted for CNS Vital Signs uses only four colors/color words (red, green, yellow, blue), and only one key, the space bar. The test has three parts. In the first section, the words "red", "yellow", "blue" and "green" appear at random on the screen, and the subject presses the space bar 
as soon as he or she sees the word, and then, the subject receives a simple reaction time score [22]. In one study of 175 patients with ADHD, patients aged 10 to 29 were compared with 175 age-matched normal controls who had taken the CNS Vital Signs battery. The ADHD group had higher Stroop test simple reaction time scores than the normal controls. A lower score on the Stroop test is considered better [23]. In both polymorphism groups, we observed an effect on Stroop simple reaction time scores. We did not find any study on ADHD, but it was shown that synapsin III protein levels significantly decreased in the prefrontal cortex of individuals with schizophrenia [24]. Additionally, hemodynamic brain imaging data both support the sensitivity and specificity of the Stroop test to indicate frontal lobe functioning [25]. Accordingly, these polymorphisms may have affected the Stroop test simple reaction time in our study via this mechanism.

\subsection{Limitations}

There are several limitations of the present study. Our study included only two ADHD subtypes (ADHD-I and ADHD-C) because ADHD-H is rarely observed clinically. Future studies that include the ADHD-H subtype would provide more comprehensive information related to the psychopathology of ADHD. We did not exclude ODD, and the presence of possible comorbid ODD in some patients may have had a confounding effect. Additionally, we assessed only estimated IQ using the vocabulary and block design subtests of the WISC-R. Thus, other potential ADHD neuropsychological domains were not assessed (e.g., delay aversion, RT variability). For the DNA source, we used a saliva sample, but peripheral blood samples could be taken to increase the efficiency of genotyping.

\subsection{Conclusion}

Attention Deficit Hyperactivity Disorder is complex and heterogeneous. It is difficult to find a particular gene associated with ADHD. Prospective studies, which followed subjects with ADHD from child- to adulthood, have shown a reduction in hyperactive and impulsive symptoms over time, but the inattentive symptoms persisted into adulthood [26]. Therefore, the expression of the main genes could be different in childhood than in adulthood. Synapsin effects could be limited during childhood but may be present in adulthood. Therefore, specific endophenotypes for attention deficit, hyperactivity and impulsivity symptoms should be determined.

\section{Acknowledgements}

No financial support has been received related to the manuscript. All authors confirm that there is no conflict of interest.

\section{References}

[1] Polanczyk, G., de Lima, M.S., Horta, B.L., Biederman, J. and Rohde, L.A. (2007) The Worldwide Prevalence of ADHD: A Systematic Review and Metaregression Analysis. The American Journal of Psychiatry, 164, 942-948. http://dx.doi.org/10.1176/ajp.2007.164.6.942

[2] Association, A.P. (2013) Diagnostic and Statistical Manual of Mental Disorders, (DSM-5®).

[3] Wolraich, M.L. (1999) Attention Deficit Hyperactivity Disorder: The Most Studied and Yet Most Controversial Diagnosis. Mental Retardation and Developmental Disabilities Research Reviews, 5, 163-168. http://dx.doi.org/10.1002/(SICI)1098-2779(1999)5:3<163::AID-MRDD1>3.0.CO;2-T

[4] Akutagava-Martins, G.C., Salatino-Oliveira, A., Kieling, C.C., Rohde, L.A. and Hutz, M.H. (2013) Genetics of Attention-Deficit/Hyperactivity Disorder: Current Findings and Future Directions. Expert Review of Neurotherapeutics, 13, 435-445. http://dx.doi.org/10.1586/ern.13.30

[5] Elia, J., Gai, X., Xie, H.M., Perin, J.C., Geiger, E., Glessner, J.T. and White, P.S. (2010) Rare Structural Variants Found in Attention-Deficit Hyperactivity Disorder Are Preferentially Associated with Neurodevelopmental Genes. Molecular Psychiatry, 15, 637-646. http://dx.doi.org/10.1038/mp.2009.57

[6] Greengard, P., Valtorta, F., Czernik, A.J. and Benfenati, F. (1993) Synaptic Vesicle Phosphoproteins and Regulation of Synaptic Function. Science, 259, 780-785. http://dx.doi.org/10.1126/science.8430330

[7] Kao, H.T., Porton, B., Hilfiker, S., Stefani, G., Pieribone, V.A., DeSalle, R. and Greengard, P. (1999) Molecular Evolution of the Synapsin Gene Family. The Journal of Experimental Zoology, 285, 360-377. http://dx.doi.org/10.1002/(SICI)1097-010X(19991215)285:4<360::AID-JEZ4>3.0.CO;2-3 
[8] Kao, H.T., Porton, B., Czernik, A.J., Feng, J., Yiu, G., Häring, M. and Greengard, P. (1998) A Third Member of the Synapsin Gene Family. Proceedings of the National Academy of Sciences of the United States of America, 95, 46674672. http://dx.doi.org/10.1073/pnas.95.8.4667

[9] Porton, B., Wetsel, W.C. and Kao, H.-T. (2011) Synapsin III: Role in Neuronal Plasticity and Disease. Seminars in Cell \& Developmental Biology, 22, 416-424. http://dx.doi.org/10.1016/j.semcdb.2011.07.007

[10] Kile, B.M., Guillot, T.S., Venton, B.J., Wetsel, W.C., Augustine, G.J. and Wightman, R.M. (2010) Synapsins Differentially Control Dopamine and Serotonin Release. The Journal of Neuroscience: The Official Journal of the Society for Neuroscience, 30, 9762-9770. http://dx.doi.org/10.1523/JNEUROSCI.2071-09.2010

[11] Herken, H., Erdal, M.E., Kenar, A.N.İ., Unal, G.A., Cakaloz, B., Ay, M.E., et al. (2014) Association of SNAP-25 Gene Ddel and Mnll Polymorphisms with Adult Attention Deficit Hyperactivity Disorder. Psychiatry Investigation, 11, 476480. http://dx.doi.org/10.4306/pi.2014.11.4.476

[12] Kenar, A.N.I., Ay, O.İ., Herken, H. and Erdal, M.E. (2014) Association of VAMP-2 and Syntaxin 1A Genes with Adult Attention Deficit Hyperactivity Disorder. Psychiatry Investigation, 11, 76-83. http://dx.doi.org/10.4306/pi.2014.11.1.76

[13] Ohtsuki, T., Ichiki, R., Toru, M. and Arinami, T. (2000) Mutational Analysis of the Synapsin III Gene on Chromosome 22q12-q13 in Schizophrenia. Psychiatry Research, 94, 1-7. http://dx.doi.org/10.1016/S0165-1781(00)00123-2

[14] Ohmori, O., Shinkai, T., Hori, H., Kojima, H. and Nakamura, J. (2000) Synapsin III Gene Polymorphisms and Schizophrenia. Neuroscience Letters, 279, 125-127. http://dx.doi.org/10.1016/S0304-3940(99)00970-2

[15] Makkar, R., Gomez, L., Wigg, K.G., Ickowicz, A., Pathare, T., Tannock, R., et al. (2007) The Gene for Synapsin III and Attention-Deficit Hyperactivity Disorder. Psychiatric Genetics, 17, 109-112. http://dx.doi.org/10.1097/YPG.0b013e328012a0c6

[16] Kenar, A.N.İ., Edgünlü, T., Herken, H. and Erdal, M.E. (2013) Association of Synapsin III Gene with Adult Attention Deficit Hyperactivity Disorder. DNA and Cell Biology, 32, 430-434. http://dx.doi.org/10.1089/dna.2012.1937

[17] Volk, H.E., Todorov, A.A., Hay, D.A. and Todd, R.D. (2009) Simple Identification of Complex ADHD Subtypes Using Current Symptom Counts. Journal of the American Academy of Child and Adolescent Psychiatry, 48, 441-450. http://dx.doi.org/10.1097/CHI.0b013e31819996ba

[18] Achenbach, T. (1991) Integrative Guide for the 1991 CBCL 4-18, YSR, and TRF Profiles. Department of Psychiatry University of Vermont, Burlington, VT.

[19] Ercan, E.S., Amado, S. and Somer, O.Ç.S. (2001) Development of a Test Battery for the Assessment of Attention Deficit Hyperactivity Disorder. Çocukve Gençlik Ruh Să̆llğg Dergisi/Turkish Journal of Child and Adolescent Mental Health, 8, 132-144.

[20] Gökler, B., Ünal, F., Pehlivantürk, Y., Kültür, E.Ç., Akdemir, D.T.Y. (2004) Reliability and Validity of Schedule for Affective Disorders and Schizophrenia for School Age Children-Present and Lifetime Version-Turkish Version (KSADS-PL-T). Çocukve Gençlik Ruh Sağlı̆̆ı Dergisi/Turkish Journal of Child and Adolescent Mental Health, 11, 109116.

[21] Leckman, J.F., Sholomskas, D., Thompson, W.D., Belanger, A. and Weissman, M.M. (1982) Best Estimate of Lifetime Psychiatric Diagnosis: A Methodological Study. Archives of General Psychiatry, 39, 879-883. http://dx.doi.org/10.1001/archpsyc.1982.04290080001001

[22] Gualtieri, C.T. and Johnson, L.G. (2006) Reliability and Validity of a Computerized Neurocognitive Test Battery, CNS Vital Signs. Archives of Clinical Neuropsychology: The Official Journal of the National Academy of Neuropsychologists, 21, 623-643. http://dx.doi.org/10.1016/j.acn.2006.05.007

[23] Gualtieri, C.T. and Johnson, L.G. (2006) Efficient Allocation of Attentional Resources in Patients with ADHD: Maturational Changes from Age 10 to 29. Journal of Attention Disorders, 9, 534-542. http://dx.doi.org/10.1177/1087054705283758

[24] Porton, B. and Wetsel, W.C. (2007) Reduction of Synapsin III in the Prefrontal Cortex of Individuals with Schizophrenia. Schizophrenia Research, 94, 366-370. http://dx.doi.org/10.1016/j.schres.2007.04.016

[25] Alvarez, J.A. and Emory, E. (2006) Executive Function and the Frontal Lobes: A Meta-Analytic Review. Neuropsychology Review, 16, 17-42. http://dx.doi.org/10.1007/s11065-006-9002-X

[26] Sobanski, E., Brüggemann, D., Alm, B., Kern, S., Philipsen, A., Schmalzried, H., et al. (2008) Subtype Differences in Adults with Attention-Deficit/Hyperactivity Disorder (ADHD) with Regard to ADHD-Symptoms, Psychiatric Comorbidity and Psychosocial Adjustment. European Psychiatry: The Journal of the Association of European Psychiatrists, 23, 142-149. http://dx.doi.org/10.1016/j.eurpsy.2007.09.007 